\title{
The Pathophysiology of the Catastrophic Antiphospholipid Syndrome: Compelling Evidence
}

\author{
Oscar-Danilo Ortega-Hernandez • \\ Nancy Agmon-Levin • Miri Blank • \\ Ronald A. Asherson • Yehuda Shoenfeld
}

(C) Humana Press Inc. 2008

This article was withdrawn due to duplicate publication.

This article was withdrawn due to duplicate publication.

O.-D. Ortega-Hernandez • N. Agmon-Levin · M. Blank •

Y. Shoenfeld

Department of Internal Medicine 'B' and Center for Autoimmune

Diseases, Chaim Sheba Medical Center, Tel Aviv University,

Tel Hashomer, Israel

\section{R. A. Asherson}

Division of Immunology, School of Pathology,

University of the Witwatersrand,

Johannesburg, South Africa

\section{Y. Shoenfeld}

Incumbent of the Laura Schwarz-Kip Chair for Autoimmunity,

Sackler-Faculty of Medicine, Tel-Aviv University,

Tel Aviv, Israel

Y. Shoenfeld $(\bowtie)$

Department of Internal Medicine "B" and Center for Autoimmune

Disease, Sheba Medical Center,

Tel Hashomer 52621, Israel

e-mail: Shoenfel@post.tau.ac.il 